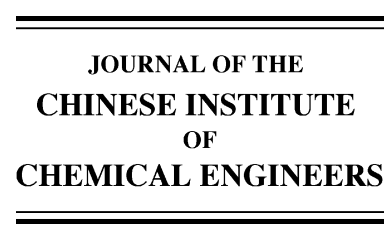

www.elsevier.com/locate/jcice

\title{
Modeling convective drying of wet cake
}

\author{
Tao Tao ${ }^{\mathrm{a}}$, Xiao-Feng Peng ${ }^{\mathrm{a}}$, Ay Su ${ }^{\mathrm{b}}$, Duu-Jong Lee ${ }^{\mathrm{c}, *}$, \\ Arun Sadashiv Mujumdar ${ }^{\mathrm{d}}$ \\ ${ }^{a}$ Laboratory of Phase Change \& Interface Transport Phenomena, Tsinghua University, Beijing 100084, China \\ ${ }^{\mathrm{b}}$ Department of Mechanical Engineering, Fuel Cell Center, Yuan-Ze University, Taoyuan 300, Taiwan \\ ${ }^{\mathrm{c}}$ Department of Chemical Engineering, National Taiwan University, Taipei 10617, Taiwan \\ ${ }^{\mathrm{d}}$ Department of Mechanical Engineering, National University of Singapore, 10 Kent Ridge Crescent, \\ 119260 Singapore, Singapore \\ Received 4 December 2007; accepted 7 December 2007
}

\begin{abstract}
This study analyzed convective drying of wastewater sludge cakes with three-dimensional cake structures probed using an X-ray microcomputerized tomography scanner (micro-CT), considering the development of cracks and cake morphology. The presence of artificial cracks on cake surface assist drying, but those occurred naturally cannot. The cake surface is noted far from saturation over drying. Moreover, the cracks transport easily moisture to cake surface, hence yielding high surface humidity (and rates) for drying. Comprehensive drying model has to incorporate real boundary conditions for success modeling.
\end{abstract}

(C) 2008 Taiwan Institute of Chemical Engineers. Published by Elsevier B.V. All rights reserved.

Keywords: Drying rate; Crack; Micro-CT; Model

\section{Introduction}

Sludge moisture content is a critical parameter governing the feasibility of various final disposal routes, such as direct land application, composting, landfill, and incineration (Lee and Liu, 2004). Prior to thermal drying, most sludge moisture is removed via mechanical approaches (Arlabosse and Chitu, 2007; Chen et al., 2006a,b; Hwang et al., 2006; Islam et al., 2007; Kung, 2006; Lee et al., 2007a,b; Novak, 2006; Otawara and Kitamura, 2006; Seginer and Bux, 2006; Seginer et al., 2007; Sheng et al., 2006; Tien and Ramarao, 2006; Vaxelaire and Olivier, 2006). Thermal drying is frequently utilized following mechanical dewatering to remove substantial amounts of moisture from sludge. Sludge cakes typically shrink in size during drying (Smollen, 1990), accompanied by the development of a hard and relatively impermeable skin layer that forms the exterior surfaces on a cake (Vaxelaire and Cezac, 2004). Tao et al. (2005a,b,c) who identified that volume

\footnotetext{
* Corresponding author.

E-mail addresses: pxf-dte@mail.tsinghua.edu.cn (X.-F. Peng), meaysu@saturn.yzu.edu.tw (A. Su),djlee@ntu.edu.tw (D.-J. Lee), mpeasm@nus.edu.sg (A.S. Mujumdar).
}

shrinkage and crack development occur simultaneously during drying, noted that ignorance of shrinkage or cracking precludes the development of a comprehensive model for dynamic behavior of sludge during cake drying. Later, Tao et al. (2006a) examined skin layer formation and development of a drying cake using an X-ray micro-computerized tomography scanner (micro-CT) and image processing techniques, and was the first to identify the correlation between the drying flux and skin layer formation.

Tao et al. (in press) developed comprehensive model exists for heat and mass transfer from a drying sludge cake. The drying process was modeled by solving governing equations for airflow in the established structural model. Boundary conditions are required for successful modeling, but adequate surface conditions at drying, including surface temperature and relative humidity that determine the heat and mass fluxes are generally lacking. In this work, we utilized the cake model developed by Tao et al. (in press) to monitor the drying process of wastewater cake, particularly on the time course of surface conditions in drying.

\section{Cake model}

The experimental setup for the drying test was the same as that used by Tao et al. (2005a). The relative humidity of air was 


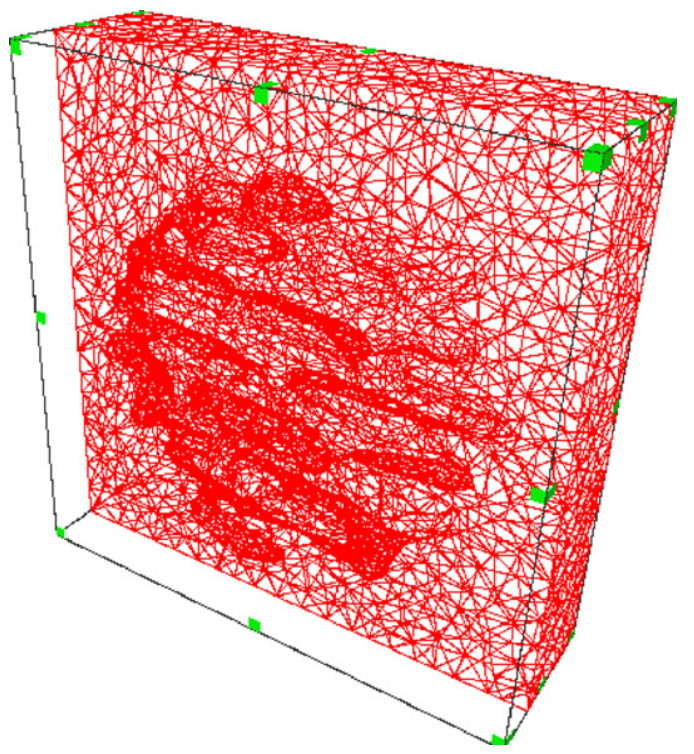

Fig. 1. The tetrahedral volumetric grids of drying cake at $1-X / X_{0}=0.84$.

$3.0 \%(\mathrm{w} / \mathrm{w})$ and temperature of $83.7{ }^{\circ} \mathrm{C}$. The air flowed over the test section at a velocity of $1 \mathrm{~m} / \mathrm{s}$. The corresponding wet bulb temperature was $30.7^{\circ} \mathrm{C}$. The sample was scanned using a micro-CT (Skyscan-1074, Skyscan, Aartselaar, Belgium) at 30min intervals. The two-dimensional reconstructed transversal section at various different heights of the drying cake over drying, with image bileveled using methods described elsewhere (Chu and Lee, 2004; Chu et al., 2004; Yang et al., 2007). Using the series of bileveled images, the three-dimensional structure of the cake was reconstructed. Amira 3.0 (TGS Inc., USA) software was utilized to reconstruct the threshold sliced images as isosurfaces (polygonal surface models) and volumetric grids for advanced finite-element simulation.

Fig. 1 presents the volumetric grids for the drying cake with cracks. The cake has a very heterogeneous structure. Models considering a drying cake as uniform are likely misleading. For simulation, the constructed cake was attached to an air channel $2.8 \mathrm{~mm} \times 2.8 \mathrm{~mm} \times 10 \mathrm{~mm}(\mathrm{~L} \times \mathrm{W} \times \mathrm{H})$. An advancingfront algorithm was applied to fill each region defined by the polygonal surface with unstructured tetrahedral volumetric grids.

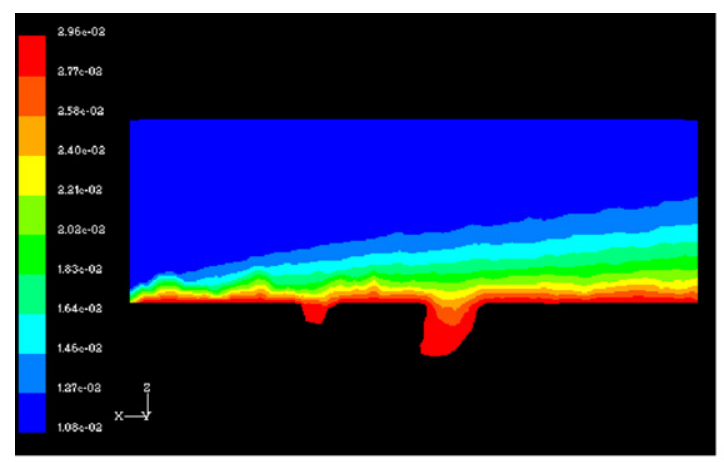

(a)

\section{Results and discussion}

\subsection{Equations and solution}

Governing equations for the air-vapor mix in the flow channel include the Reynolds average Navier-Stokes equations, energy equation, diffusion equation, and $k-\varepsilon$ turbulent equations. These equations are as follows:

$\frac{\partial(\rho \phi)}{\partial t}+\frac{\partial}{\partial x_{j}}\left(\rho u_{j} \phi\right)=\frac{\partial}{\partial x_{j}}\left(D_{\phi} \frac{\partial \phi}{\partial x_{j}}\right)+S_{\phi}$

where $\phi, D_{\phi}$ and $S_{\phi}, r$, are dependent variables, diffusion coefficients, source terms, and fluid density, respectively. The definitions of terms in Eq. (1) are the same as those used in Tao et al. (2006b), where $G_{\mathrm{K}}$ is the turbulent fluctuation, and $\mu_{\mathrm{t}}$ is turbulent viscosity. Restated, the continuity equation, momentum equation, energy equation, diffusion equation, $\kappa$ equation, and $\varepsilon$ equation for Eq. (1) are $\phi=1, u_{j}(j=1-3), T, C$, $k$, and $\varepsilon ; D_{\phi}=0, \mu+\mu_{\mathrm{t}}, \mu / \operatorname{Pr}+\mu_{\mathrm{t}} / \sigma_{\mathrm{T}}, \mu / \mathrm{Sc}+\mu_{\mathrm{t}} / \sigma_{\mathrm{C}}, \mu+\mu_{\mathrm{t}} / \sigma_{\mathrm{k}}$, $\mu+\mu_{\mathrm{t}} / \sigma_{\varepsilon}, ; 0,-\partial p / \partial x_{i}+\partial\left[\left(\mu+\mu_{\mathrm{t}}\right)\left(\partial u_{j} / \partial x_{i}\right)\right] / \partial x_{j}, 0,0, G_{\mathrm{k}}-\rho \varepsilon$, $(\varepsilon / k)\left(c_{1} G_{k}-c_{2} \rho \varepsilon\right)$, respectively.

The hexahedral grids generated using Amira 3.0 were first preprocessed using the geometry modeling/mesh generation software GAMBIT 2.0 (Fluent Inc., USA) to define the inlet,

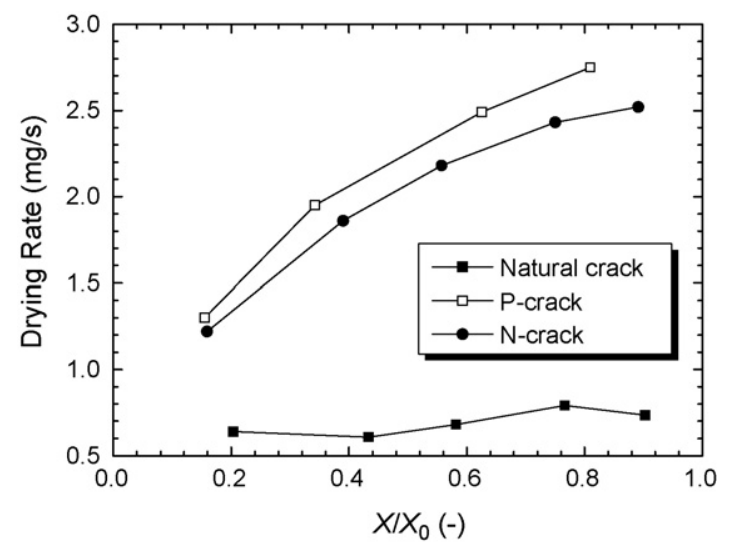

Fig. 3. Calculated overall drying rates from the drying cakes with residual moisture contents.

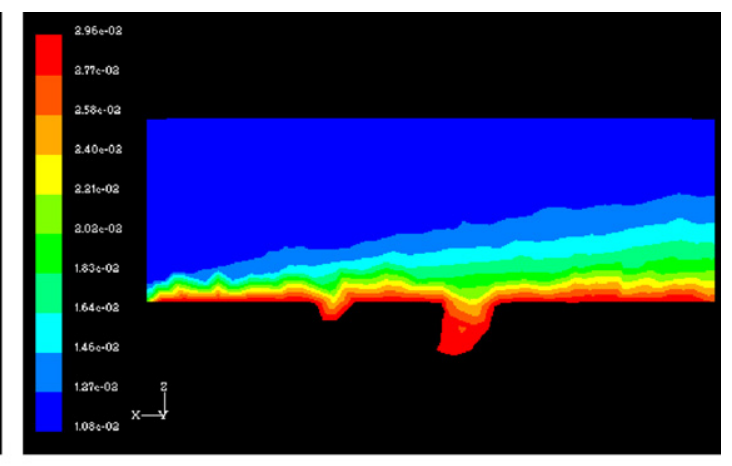

(b)

Fig. 2. Iso-humidity plots in the cake-channel model. Flow from left to right at $1 \mathrm{~m} / \mathrm{s}$. Inlet air temperature $=83.7{ }^{\circ} \mathrm{C}$, surface temperature of cake $=30{ }^{\circ} \mathrm{C}$. (a) 94,813 grids; (b) 29,132 grids. 

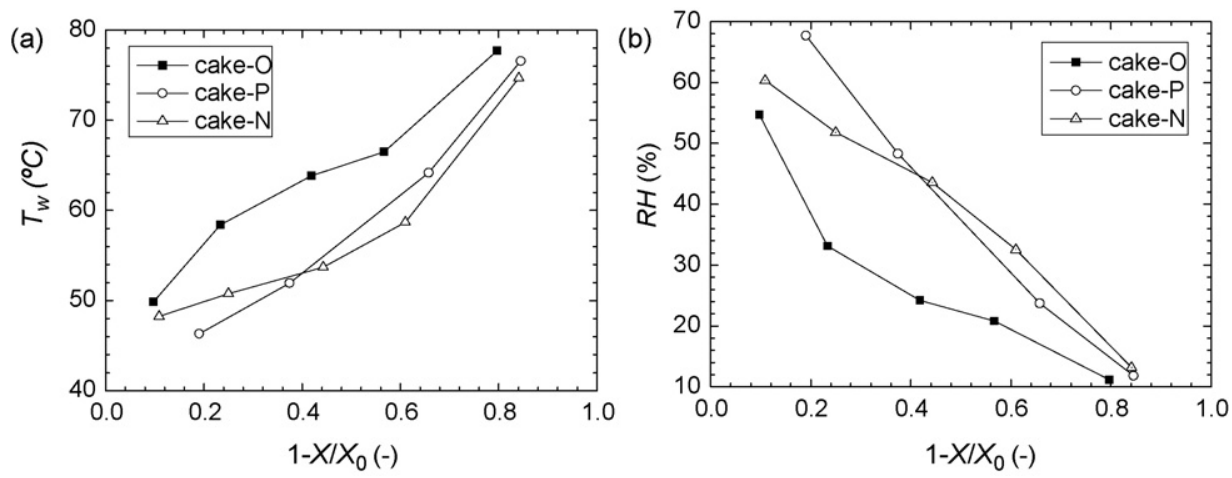

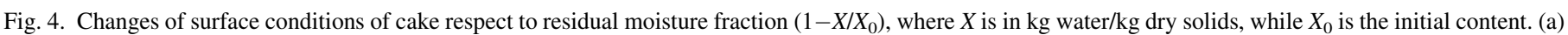
Change in surface temperature. (b) Change in relative humidity.

outlet and walls, for solving governing Eq. (1), subject to associated boundary conditions. Thermal conductivity $(\lambda)$, fluid viscosity $(\mu)$, and diffusion coefficient $(D)$ of fluid were $0.0303 \mathrm{~W} / \mathrm{m} \mathrm{K}, 2.23 \times 10^{-5} \mathrm{~kg} / \mathrm{m} \mathrm{s}$, and $3.35 \times 10^{-5} \mathrm{~m} / \mathrm{s}$, respectively. Turbulence intensity $I$ and hydraulic diameter $D_{\mathrm{H}}$ at the inlet were $5.6 \%$ and $0.1 \mathrm{~m}$, respectively.

\subsection{Grids and accuracy}

To assure numerical accuracy models with different grid numbers were tested. The corresponding numbers of grids are $94,813,29,132,10,863$, and 3812, respectively. A boundarylayer developed along the flow direction as humidity declined when moving away from the cake surface (Fig. 2). The windward side of cake dried faster than the downwind side. It is recognized that the calculations with 29,132 grids can approximate the real process while the calculations with 10,863 grids or less cannot (not shown).

\subsection{Simulating drying cake}

Experimental drying rates are available in Tao et al. (in press). In calculations the surface temperature, hence the relative humidity at cake surface were first guessed, then the entire equation set of Eq. (1) were solved numerically. Then the overall drying rates calculated were compared with the experimental data. Iteration led to converged results and estimated the corresponding surface conditions. Next only the convergent results are discussed further.

The drying rates for cakes with cracks can be estimated using the constructed model. The drying rate for cracks follows the P-crack $>$ N-crack $\gg$ natural cracks (Fig. 3). The effects of direct convective flow through the cracks were minimal. Conversely, the cake with naturally formed cracks achieved a low drying rate over the drying test. Restated, the drying rate was low, yielding a fake "constant-rate period". During drying, the surface temperature increased and the relative humidity decreased with decreasing moisture content (Fig. 4). Moreover, the cake surface was far below unsaturated in all tests, which contradict the common assumption in drying models. At the same moisture content, the surface temperature of original cake (cake-O with natural cracks) was higher than those with artificial cracks (Fig. 4(a)), whereas the corresponding surface relative humidity for cake-O was lower than the other cakes. Such an observation has significant impacts to efforts for developing comprehensive during model for wastewater cakes.

\section{Conclusions}

Grid models of dewatered cake collected from the Beijing GaoBeiDian Sewage Treatment Plant, yielded by threedimensional reconstruction of micro-CT scanned, two-dimensional reconstructed transversal sections of the cake, were utilized to model wastewater sludge cake drying. During convective drying a mass boundary-layer was developed along the flow direction, with the windward side of cake dried faster than the downwind side. The cake with artificial cracks assists drying. However, the orientation of the cracks minimally affected the drying rates. During drying, the surface temperature increased and the relative humidity decreased with decreasing moisture content. The cake surface was far from saturation, inconsistent with the common approximation that a cake was wet at the drying surface. The cake with artificial cracks exhibited higher surface humidity in drying, probably owing to the easy mass transfer through crack regime to cake surface in drying. Comprehensive drying model has to incorporate real boundary conditions for success modeling.

\section{References}

Arlabosse, P. and T. Chitu, "Identification of the Limiting Mechanism in Contact Drying of Agitated Sewage Sludge," Dry. Technol., 25, 557 (2007).

Chen, Y. S., C. Y. D. Tai, M. H. Chang, and H. S. Liu, "Characteristics of Micromixing in a Rotating Packed Bed," J. Chin. Inst. Chem. Engrs., 37, 63 (2006a).

Chen, B. H., S. J. Lee, D. J. Lee, and L. Spinosa, "Rheological Behavior of Wastewater Sludge Following Polyeletrolyte Flocculation," Dry. Technol., 24, 1289 (2006b).

Chu, C. P. and D. J. Lee, "Bilevel Thresholding of Sliced Image of Sludge Floc," Environ. Sci. Technol., 38, 1161 (2004).

Chu, C. P., D. J. Lee, and J. H. Tay, "Bilevel Thresholding of Floc Images," J. Colloid Interf. Sci., 273, 483 (2004).

Hwang, K. J., S. F. You, and T. M. Don, "Disruption Kinetics of Bacterial Cells During Purification of Poly-beta-Hydroxyalkanoate Using Ultrasonication," J. Chin. Inst. Chem. Eng., 37, 209 (2006). 
Islam, M. R., K. S. Thaker, and A. S. Mujumdar, "A Diffusion Model for a Drum Dryer Subjected to Conduction, Convection, and Radiant Heat Input," Dry. Technol., 25, 1033 (2007).

Kung, H. H., "Nanotechnology: Opportunity for Chemical Engineering," $J$. Chin. Inst. Chem. Engrs., 37, 1 (2006).

Lee, D. J. and J. C. Liu, "Route to Synthesize the Sludge Management Processes," Water Sci. Technol., 49, 259 (2004).

Lee, D. J., J. Y. Lai, and A. S. Mujumdar, "Moisture Distribution and Dewatering Efficiency for Wet Materials," Dry. Technol., 24, 1201 (2007a).

Lee, J. E., J. K. Lee, and H. K. Choi, "Filter Press for Electrodewatering of Waterworks Sludge," Dry. Technol., 25, 1649 (2007b).

Novak, J., "Dewatering of Sewage Sludge," Dry. Technol., 24, 1257 (2006).

Otawara, K. and T. Kitamura, "Comparison of a Belt-Filter and Centrifuge in the Crystal Purification Process with CDC (Cooling Disc Crystallizer) and KCP (Kureha Crystal Purifier)," J. Chin. Inst. Chem. Engrs., 37, 509 (2006).

Seginer, I. and M. Bux, "Modeling Solar Drying Rate of Wastewater Sludge," Dry. Technol., 24, 1353 (2006).

Seginer, I., I. Ioslovich, and M. Bux, "Optimal Control of Solar Sludge Dryer," Dry. Technol., 25, 401 (2007).

Sheng, W. Y., X. F. Peng, D. J. Lee, and A. Su, "Coagulation of Particles Through Rapid Mixing," Dry. Technol., 24, 1271 (2006).

Smollen, M., "Evaluation of Municipal Sludge Drying and Dewatering with Respect to Sludge Volume Reduction," Water Sci. Technol., 11, 153 (1990).
Tao, T., X. F. Peng, and D. J. Lee, "Thermal Drying of Wastewater Sludge: Volume Shrinkage and Crack Development," Dry. Technol., 23, 669 (2005a).

Tao, T., X. F. Peng, and D. J. Lee, "Structure of Crack in Thermally Dried Sludge Cake," Dry. Technol., 23, 1555 (2005b).

Tao, T., X. F. Peng, and D. J. Lee, "Crack Dynamics of Thermally Dried Cake," J. Chin. Inst. Chem. Engrs., 36, 511 (2005c).

Tao, T., X. F. Peng, and D. J. Lee, "Skin Layer on Thermally Dried Cake," Dry. Technol., 24, 1047 (2006a).

Tao, T., X. F. Peng, and D. J. Lee, "Interaction between Ice and Floc under Freezing," J. Chin. Inst. Chem. Engrs., 37, 299 (2006b).

Tao, T., X.F. Peng, A. Su, A.S. Mumjudar, and D.J. Lee. "Model for Sludge Cake Drying Accounting for Developing Cracks". Dry. Technol., in press.

Tien, C. and B. V. Ramarao, "On Analysis of Cake Formation and Growth in Cake Filtration," J. Chin. Inst. Chem. Engrs., 37, 81 (2006).

Vaxelaire, J. and P. Cezac, "Moisture Distribution in Activated Sludges: A Review," Water Res., 38, 2215 (2004).

Vaxelaire, J. and J. Olivier, "Conditioning for Municipal Sludge Dewatering. From Filtration Compression Cell Tests to Belt Press," Dry. Technol., 24, 1225 (2006).

Yang, Z., X. F. Peng, C. P. Chu, and D. J. Lee, "Image Processing and Gemoetric Parameters Extracted from Sliced Image of Porous Biomaterial," Adv. Powder Technol., 18, 187 (2007). 